\title{
Metastatic Extraskeletal Myxoid Chondrosarcoma
}

National Cancer Institute

\section{Source}

National Cancer Institute. Metastatic Extraskeletal Myxoid Chondrosarcoma. NCI

Thesaurus. Code C8804.

An extraskeletal myxoid chondrosarcoma which has spread to another anatomic site. 